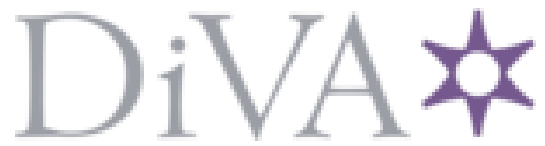

http://www.diva-portal.org

This is the published version of a paper published in Scandinavian Journal of Work, Environment and Health.

Citation for the original published paper (version of record):

Tinc, P J., Jenkins, P., Sorensen, J A., Weinehall, L., Gadomski, A. et al. (2020)

Key factors for successful implementation of the National Rollover Protection

Structure Rebate Program: A correlation analysis using the consolidated framework for implementation research

Scandinavian Journal of Work, Environment and Health, 46(1): 85-95

https://doi.org/10.5271/sjweh.3844

Access to the published version may require subscription.

N.B. When citing this work, cite the original published paper.

Permanent link to this version:

http://urn.kb.se/resolve?urn=urn:nbn:se:umu:diva- 162438 


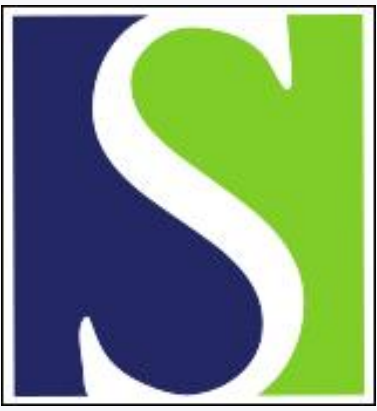

\section{Original article}

Scand J Work Environ Health 2020;46(1):85-95

doi:10.5271/sjweh.3844

Key factors for successful implementation of the National Rollover Protection Structure Rebate Program: A correlation analysis using the consolidated framework for implementation research

by Tinc PJ, Jenkins P, Sorensen JA, Weinehall L, Gadomski A, Lindvall K

This manuscript applies the clinically based consolidated framework for implementation research (CFIR) to the national level implementation of an occupational safety initiative proven to save lives. Importantly, this manuscript identifies the CFIR constructs that are most highly correlated with outcome measures demonstrating Program success and provides insight for others working on similar initiatives or in similar settings.

Affiliation: Northeast Center for Occupational Health and Safety: Agriculture, Forestry, and Fishing, 1 Atwell Road, Cooperstown, NY 13326, USA. pam.tinc@bassett.org

Key terms: agriculture; consolidated framework for implementation research; correlation analysis; factor; implementation; National Rollover Protection Structure Rebate Program; occupational safety; rollover; safety; scale-up; stakeholder engagement

This article in PubMed: www.ncbi.nlm.nih.gov/pubmed/31365746

\section{Additional material}

Please note that there is additional material available belonging to this article on the Scandinavian Journal of Work, Environment \& Health -website. 


\title{
Key factors for successful implementation of the National Rollover Protection Structure Rebate Program: A correlation analysis using the consolidated framework for implementation research
}

\author{
by Pamela J Tinc, PhD, ${ }^{1,2}$ Paul Jenkins, PhD, ${ }^{1,3}$ Julie A Sorensen, PhD, ${ }^{1}$ Lars Weinehall, MD, ${ }^{2}$ Anne Gadomski, MD, ${ }^{3}$ Kristina \\ Lindvall, PhD ${ }^{2}$
}

\begin{abstract}
Tinc PJ, Jenkins P, Sorensen JA, Weinehall L, Godomski A, Lindvall K. Key factors for successful implementation of the National Rollover Protection Structure Rebate Program: A correlation analysis using the consolidated framework for implementation research. Scand J Work Environ Health. 2020;76(1):85-95. doi:10.5271/sjweh.3844
\end{abstract}

\begin{abstract}
Objectives On US farms, tractor overturns are the leading cause of death; however, these fatalities are preventable with the use of a rollover protection structure (ROPS). A ROPS rebate program was established in New York in 2006 to address these fatalities. Due to its success, the program expanded to six additional states before being implemented as the National ROPS Rebate Program (NRRP) in 2017. The aim of this study was to evaluate the success of the NRRP implementation using short- and long-term ROPS outcome measures and identify which components of the consolidated framework for implementation research (CFIR) correlate with these outcomes.

Methods Stakeholders involved in the NRRP implementation were surveyed at four time points, beginning at the time of the NRRP launch and then every six months. These surveys measured 14 relevant CFIR constructs. Correlations between CFIR survey items (representing constructs) and three outcome measures (intakes, funding progress, and retrofits) were used to identify CFIR survey items that are predictive of the outcomes.

Results Eight CFIR survey items were highly correlated (rho $\geq 0.50$ ) with at least one of the three outcome measures. These eight CFIR survey items included four constructs: access to knowledge and information, leadership engagement, engaging (in fundraising and funding requests), and reflecting and evaluating.

Conclusions The results of this study provide important guidance for continuing the implementation of the NRRP. Similarly, these findings can inform the evaluation of other similarly structured implementation efforts and the application of CFIR in a variety of settings.
\end{abstract}

Key terms agriculture; occupational safety; safety; scale-up; stakeholder engagement.

Agricultural workers face one of the highest rates of fatal occupational injuries in the US (24.0 fatal injuries per 100000 workers, compared to the all-worker fatality rate of 3.5 fatalities per 100000 workers) (1). Agricultural workers also face high non-fatal injury rates; the Bureau of Labor Statistics reports 5.7 non-fatal injuries per 100 workers for the agriculture, forestry, and fishing sector (2). This number, however, may be low, as it is likely injuries are considerably underreported by these occupational groups (3). Given these statistics, it is evident that agricultural health and safety is a vital component of public health efforts.
Though much has been done to identify viable solutions to common health and safety issues in agriculture, little research has focused on how to translate these solutions into widespread practice (4-6). At the time of this study, no other published efforts to scale-up agricultural safety interventions could be found. While in some cases, this is likely the result of a limited and inconsistent understanding of what it truly means to translate research into practice (5), another major barrier to such work is a lack of understanding of what works (or does not) in translating occupational health and safety innovations to practice and why translational successes or failures occur (4-6).

1 Northeast Center for Occupational Health and Safety: Agriculture, Forestry, and Fishing, Cooperstown, NY, USA.

2 Department of Epidemiology and Global Health, Umeå University, Umeå, Sweden.

3 Research Institute, Bassett Medical Center, Cooperstown, NY, USA.

Correspondence to: Pamela J Tinc, Northeast Center for Occupational Health and Safety: Agriculture, Forestry, and Fishing, 1 Atwell Road, Cooperstown, NY 13326, USA. [E-mail: pam.tinc@bassett.org] 
Despite slow progress in agricultural safety and health implementation research, implementation science efforts have rapidly expanded in the areas of clinical medicine and public health. In particular, implementation researchers have sought to develop frameworks or models that can answer key questions about the implementation process. The consolidated framework for implementation research (CFIR) is one such model that was developed in order to answer questions of what works, in what settings, and why. This study uses the CFIR to quantitatively evaluate the scaling up of an agricultural safety initiative to the national level in order to provide valuable information about implementing evidence-based agricultural safety interventions.

The CFIR was developed as a tool for use in health services, including primarily clinical medicine, but also public health $(7,8)$. Development of the CFIR began with a review of the literature on theories, frameworks, and models for implementation efforts, and resulted in the combination of 19 of these into one cohesive framework (8). The CFIR was selected as an evaluation tool for this study due to its comprehensive nature and its ability to be adapted for and applied to diverse settings.

The CFIR consists of five domains related to implementation efforts: individual characteristics, inner setting, outer setting, intervention characteristics, and process $(7,8)$. In addition, supplemental domains, including implementation outcomes and client outcomes, were developed to further describe implementation efforts (9). Each of the CFIR domains have been developed in relation to various constructs, which help describe each aspect of the implementation (table 1).

The individual characteristics domain consists of five constructs that help describe different qualities of the individuals involved in the implementation process. The inner setting is intended to describe the interactions between these individuals, as well as the immediate implementation environment. This domain uses five constructs and nine sub-constructs. The outer setting, which includes four constructs, describes the influences from stakeholders and networks outside of the inner setting implementation team.

As the name suggests, the intervention characteristics domain includes eight constructs that describe the qualities of the intervention throughout the implementation process. The process domain, which includes four constructs and four sub-constructs, logically helps to describe how the implementation occurs. Finally, implementation outcomes (five constructs) and client outcomes (two constructs) help explain whether the implementation was successful.

Because the CFIR has been developed from other implementation frameworks, the construct definitions and suggested questions have been validated individually over time $(7,10)$. In addition, the CFIR as a frame-
Table 1. The consolidated framework for implementation research (CFIR) and supplemental outcome domains and constructs adapted from Damschroder et al (8) and Proctor et al (9).

\begin{tabular}{ll}
\hline Domains & Constructs \\
\hline $\begin{array}{l}\text { CFIR } \\
\text { Individual }\end{array}$ & Knowledge and beliefs about the intervention \\
characteristics & Individual stage of change \\
& Individual identification with the organization \\
& Self-efficacy \\
& Other personal attributes \\
Inner setting & Culture \\
& Implementation climate \\
& Networks and communication \\
& Readiness for implementation \\
& Structural characteristics \\
Outer setting & Cosmopolitanism \\
& External policy and incentives \\
& Patient needs and resources \\
Intervention & Peer pressure \\
characteristics & Adaptability \\
& Complexity \\
& Cost \\
& Design quality and packaging \\
& Evidence strength and quality \\
Intervention source \\
Relative advantage \\
Process & Trialability \\
& Engaging \\
Client & Executing \\
Implementation & Planning \\
& Reflecting and evaluating \\
& Acceptability \\
& Adoption \\
Appropriateness \\
Feasibility \\
Penetration \\
Sustainability \\
Satisfaction \\
\hline
\end{tabular}

work has been assessed for validity through a systematic review of its use (11). Despite these assessments, no applications of the CFIR to the agricultural safety setting could be found with the exception of this study's predecessor, which served to develop the survey instrument applied in this study (12). Thus, the utility of the CFIR in agricultural safety settings has yet to be determined.

Within agriculture, tractor overturns have long been the leading cause of death (13). These fatalities can be prevented by using rollover protection structures (ROPS), which are designed to keep tractor operators in a protected zone in the event of a tractor overturn. Though ROPS became standard on newly manufactured tractors in 1985 (14), approximately $40-50 \%$ of tractors on US farms currently lack the devices $(13,15)$. This is in large part due to the extended lifespan of most tractors, combined with the high cost (approximately $\$ 1200$ per kit) and time required to retrofit these older tractors with ROPS $(16,17)$. In addition, because many farmers do not feel personally vulnerable to tractor overturns, it can be difficult to justify the cost associated with retrofitting (16).

The ROPS rebate program was first launched in New York in 2006 after several years of formative research 
to better understand farmers' barriers and motivators to installing the safety devices $(16,17)$. An initial pilot study confirmed that targeted messaging combined with technical assistance and a monetary incentive was the key to increasing the number of ROPS-equipped tractors on farms (18). Since then, more than a decade of research has been conducted and has established the ROPS rebate program as efficacious, effective, and economical (16-25).

Between 2010 and 2016, this program was expanded to, and proved effective in, six additional states: Vermont, Pennsylvania, New Hampshire, Wisconsin, Massachusetts, and Minnesota $(19,24)$. In all, over 2800 tractors have been retrofitted to date. Further, in annual surveys distributed to all who have retrofitted tractors through the program, farmers have self-reported 17 overturn events in which the tractor operator was likely to have been saved as a direct result of the ROPS, and more than 220 close calls and other events, such as near overturns and falling objects (26).

In 2014, researchers, industry partners, farmers, private corporations, the media, and agricultural, financial, government, and health and safety organizations from across the country joined together to form the National Tractor Safety Coalition (NTSC) and moved toward expanding the existing ROPS rebate programs (27-29). The multi-sector group, led by a steering committee of 15 representatives, has worked together over the last several years to launch the national ROPS rebate program (NRRP) in June 2017 (30).

The NRRP intervention includes three primary components: (i) a toll-free hotline and website (www.ROPSr4u.com), (ii) funding for $70 \%$ rebates toward the cost of purchasing and installing ROPS, and (iii) a social marketing campaign to encourage farmers to participate. Though a small pool of rebate funding is available at the national level, individual states are encouraged to identify state-allocated funding for rebates. Currently, national level funding is too sparse to implement the social marketing campaign in states without state-allocated funding, leaving only the tollfree hotline and website in all but the seven states previously mentioned. Once fully implemented, the NRRP will provide all of the above components, including adequate rebate funding, across all 50 states.

To achieve full implementation, a two-part strategy is currently underway to encourage adoption and sustainment of these components of the NRRP intervention. This implementation strategy includes NTSC support (information and guidance, promotion, and fundraising) and a media advocacy campaign to increase nonfarming, stakeholder support of the NRRP. Though not all 50 states have NTSC members, these implementation strategy components are available nationwide.

The aim of this study was to evaluate the success of the NRRP implementation using short- and long-term ROPS outcome measures and identify which components of the CFIR are correlated with these outcomes.

\section{Methods}

\section{Data collection}

Study timing. The soft launch of the program, which occurred in March 2017, involved rebranding of the ROPS rebate programs into the NRRP and updating the website and program database. This occurred prior to the official launch (June 2017) so that technical issues related to the updates could be corrected before the public announcement. This study took place during a 24-month timeframe surrounding the NRRP implementation, beginning six months prior to and ending 18 months after the soft launch.

NRRP implementation regions. The 50 states were divided into ten implementation regions (table 2 and figure 1). These ten regions were defined based on three factors: (i) geographic location, (ii) the requirement that at least one NTSC member resided in the region at each data collection point, and (iii) the availability of different NRRP intervention components.

All 50 states have access to the toll-free hotline and website. Additionally, states in regions one, two, and three had secured at least some state-allocated funding prior to March 2017 and subsequently implemented the social marketing campaign. Region one (New York) was separated from regions two and three because the program originated in New York and had been active there for the longest period of time. Regions two and three were divided based on geographic location (region two $=$ Vermont, New Hampshire, Pennsylvania, and Massachusetts located in the Northeast, region three $=$ Wisconsin and Minnesota located in the Midwest). As described, the remaining regions (four through ten) all have access to the toll-free hotline and website and limited national-level funding. However, state-allocated funding and social marketing campaigns are not available in these states.

Measurement of CFIR constructs. In a prior study, NTSC members $(\mathrm{N}=65)$ were asked to score CFIR constructs from "not at all important" to "extremely important" to the NRRP implementation (12). Using these responses, program evaluators with backgrounds in clinical medicine, public health, anthropology, and implementation science developed a corresponding survey instrument containing 36 questions (termed "CFIR survey items") that covered 14 constructs (supplementary material, www. 
Table 2. Ten national ROPS rebate programs implementation regions and the intervention components currently available in each region.

\begin{tabular}{|c|c|c|c|c|}
\hline Region & States & $\begin{array}{l}\text { Hotline \& } \\
\text { website }\end{array}$ & $\begin{array}{l}\text { Rebate } \\
\text { funding }\end{array}$ & $\begin{array}{c}\text { Social } \\
\text { marketing }\end{array}$ \\
\hline 1 & New York & $x$ & $x$ & $x$ \\
\hline 2 & $\begin{array}{l}\text { Vermont, New Hampshire, } \\
\text { Pennsylvania, Massachusetts }\end{array}$ & $X$ & $x$ & $x$ \\
\hline 3 & Wisconsin, Minnesota & $X$ & $X$ & $x$ \\
\hline 4 & $\begin{array}{l}\text { Maine, Rhode Island, Connecticut, } \\
\text { Delaware, Maryland, New Jersey, } \\
\text { Virginia, West Virginia, Ohio }\end{array}$ & $X$ & & \\
\hline 5 & $\begin{array}{l}\text { Michigan, Illinois, Indiana, lowa, } \\
\text { Missouri, Kentucky }\end{array}$ & $X$ & & \\
\hline 6 & $\begin{array}{l}\text { North Carolina, South Carolina, } \\
\text { Georgia, Florida }\end{array}$ & $X$ & & \\
\hline 7 & $\begin{array}{l}\text { Tennessee, Mississippi, Alabama, } \\
\text { Arkansas, Louisiana }\end{array}$ & $X$ & & \\
\hline 8 & $\begin{array}{l}\text { Texas Oklahoma, New Mexico, } \\
\text { Arizona }\end{array}$ & $X$ & & \\
\hline 9 & $\begin{array}{l}\text { Nebraska, Colorado, Wyoming, } \\
\text { Kansas, South Dakota, North } \\
\text { Dakota, Montana }\end{array}$ & $x$ & & \\
\hline 10 & $\begin{array}{l}\text { Washington, Oregon, California, } \\
\text { Idaho, Nevada, Alaska, Hawaii }\end{array}$ & $x$ & & \\
\hline
\end{tabular}

sjweh.fi/show_abstract.php?abstract_id=3844) (12).

Surveys were conducted at four time points - March 2017, September 2017, March 2018, and September 2018 - with each survey asking participants to reflect on the six months prior. Thus, the surveys relate to four six-month periods: September 2016 through February 2017 (period one), March through August 2017 (period two), September 2017 through February 2018 (period three), and March through August 2018 (period four). The first time point, March 2017, served as a baseline measurement as it was collected at the time of the softlaunch of the NRRP. The additional three time points served to capture change over time in CFIR constructs.

Each survey was distributed to all members of the NTSC that were active in the coalition at the time of the surveys $(\mathrm{N}=56-68$ at each data collection point). This number fluctuated due to factors such as NTSC members' retiring and new NTSC members joining; however, overall the number of responses from each region remained relatively stable over time. At each data collection point, a mixed-mode survey method (31) was used to improve response rates: (i) Day 1: an invitation to participate in the survey was emailed to all participants. Included in this invitation was an explanation of the study and ethics information, as well as a link to the web-based survey. (ii) Day 8: Mailed packets were sent to non-responders. These packets included the contents of the original invitation, as well as a paper survey and an addressed, stamped envelope. (iii) Day 15: A "thank you" and reminder email was sent to the entire NTSC. (iv) Day 22: Non-responders were contacted via telephone. Participants had the option of completing the survey over the phone, if they wished. Participants were called up to three times. (v) Day 29:
The survey was closed.

Participants who responded to surveys were provided with one entry per survey for a $\$ 1,000$ Amazon gift card raffle. The Mary Imogene Bassett Hospital Institutional Review Board approved this study (project \#2015).

\section{Short-term outcome measure: progress}

For each six-month survey period, the project team (consisting of two researchers, the hotline coordinator, and the marketing coordinator) assigned each state a progress score between $0-6$, where $0=$ no program and no known fundraising activity and $6=$ current program with sufficient funding (table 3 ). program records (such as email correspondence and meeting notes) were used to determine these scores. This seven-level outcome was termed "progress."

\section{Long-term outcome measures: Intakes and retrofits}

Using the NRRP hotline, the number of individuals who sign up for the program ("intakes") as well as the number of tractors that were retrofitted ("retrofits") are regularly tracked. These data were obtained for each of the ten intervention regions between 1 September 2016 and 31 August 2018. For individuals completing both an intake and a retrofit during the study period, only the retrofit was counted; however, the date used was reflective of the intake date. For example, if a participant completed an intake in January 2017 and then completed the retrofit in March 2017 they were counted as a retrofit in January 2017 (period 1).

\section{Data analysis}

The change in each of the 36 CFIR survey items was compared between the ten regions over the four time periods using a four by ten mixed analysis of variance (ANOVA). The F-test for the interaction of region by time was used to evaluate whether the change in each item over time was significantly different between the regions. This same four by 10 model was used to analyze the changes in the three outcomes: retrofits, intakes, and progress scores.

The ANOVA models described above did not find significant time or region by time interaction effects. Because of this, the data were aggregated across the four time periods for each region by taking the mean value. This was done both for the CFIR survey items and the three outcomes.

The correlations between these time-averaged CFIR survey items and the three outcomes were analyzed using Spearman's rho. Due to the small sample size $(\mathrm{N}=10$ regions), these correlational analyses had limited statistical power, which presented the possibility that CFIR 


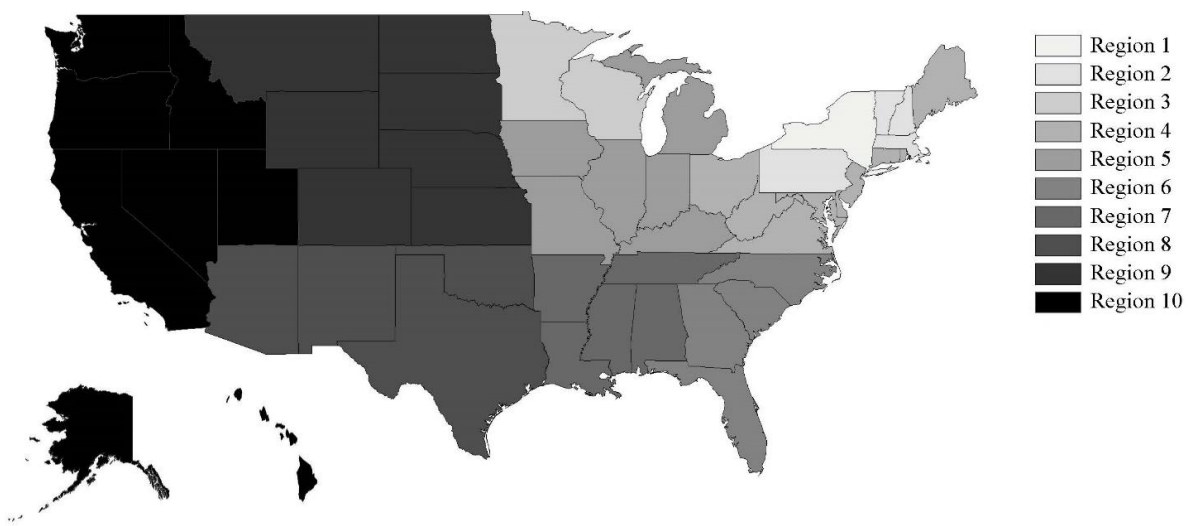

Figure 1. Tennational ROPS rebate program implementation regions.
Table 3. Rubric for scoring progress in securing funding for the National ROPS Rebate Program.

\begin{tabular}{ll}
\hline Score & Description \\
\hline 0 & No program and no known fundraising activity \\
1 & No program but information requested \\
2 & No program but planning for fundraising \\
3 & No program but actively pursuing funding \\
4 & Current program with insufficient funding \\
5 & Current fundraising to supplement funding \\
6 & Current program with sufficient funding \\
\hline
\end{tabular}

survey items with correlations of practical relevance were not necessarily statistically significant. Therefore, any Spearman's correlation between a CFIR survey item and an outcome of $\geq 0.50$ was deemed to be predictive of the outcome regardless of the significance level.

\section{Results}

\section{Descriptive statistics}

The response rates for the surveys were 50.0\%, 49.2\%, $60.7 \%$, and $67.9 \%$ for the first, second, third, and fourth surveys, respectively. The mean scores for each CFIR item can be found in table 4 .

Over the study period, there was a total of 1445 intakes and 404 retrofits across all regions. Average progress, intakes, and retrofits are shown for each region and period in table 5. As can be seen in the table, most of the intakes, nearly all of the retrofits, and the highest progress scores are in the regions 1,2, and 3, all of which had obtained funding for rebates prior to this study.

\section{Correlation analysis}

Table 6 shows the correlations between CFIR survey items and outcomes of $\geq 0.50$. For clarity, these CFIR survey items are numbered in the table and will be referred to by number in the text.

As shown in table 6, a total of eight CFIR survey items were correlated with one or more of the three outcome measures. CFIR survey items two and three were correlated with both progress and retrofits, and CFIR survey items one, four, six, and seven were correlated with all three outcome variables. These eight CFIR survey items covered four constructs in two domains: access to knowledge and information (inner setting), leadership engagement (inner setting), engaging (process), and reflecting and evaluating (process). Those that correlated with all three outcome variables included CFIR survey items related to access to knowledge and information (inner setting) and engaging (process).

\section{Discussion}

CFIR survey items that are highly correlated with all three outcomes may be the most important in moving forward with the NRRP implementation. These CFIR survey items include NTSC members' belief that part of their role is to raise funds for the program (CFIR survey item six) as well as their active role in submitting funding applications (CFIR survey item seven). This is intuitive, in that the short-term outcomes and the success of the program reflect fundraising for rebate dollars. As such, those states with pre-established funding (regions 1, 2, and 3) were, as expected, the most successful in terms of outcomes. Despite this, some small successes occurred in other regions, including movement toward higher progress scores and a handful of intakes in each region for each time point. Progress scores $>0$ indicate that the efforts put forth to implement the NRRP have been marginally successful. However, it is also important to note that securing funding (ie, reaching a progress score of 4 or 6 ) for this type of initiative can take longer 
Table 4. Mean consolidated framework for implementation research (CFIR) survey item scores for each region across all four periods.

\begin{tabular}{|c|c|c|c|c|c|c|c|c|c|c|c|c|}
\hline \multirow[t]{2}{*}{ Domain } & \multirow[t]{2}{*}{ Construct } & \multirow[t]{2}{*}{ CFIR survey item } & \multicolumn{10}{|c|}{ Region } \\
\hline & & & 1 & 2 & 3 & 4 & 5 & 6 & 7 & 8 & 9 & 10 \\
\hline \multirow{2}{*}{$\begin{array}{l}\text { Individual } \\
\text { characteristics }\end{array}$} & Knowledge and & It is feasible to implement the program. & 4.5 & 4.2 & 3.9 & 4.7 & 3.7 & 4.0 & 4.6 & 4.0 & 4.4 & 4.0 \\
\hline & $\begin{array}{l}\text { beliefs about the } \\
\text { intervention }^{\text {a }}\end{array}$ & The implementation of the program is going well. & 4.1 & 4.0 & 3.6 & 4.0 & 3.3 & 3.3 & 4.0 & 3.8 & 3.8 & 3.8 \\
\hline \multirow[t]{6}{*}{ Inner setting } & $\begin{array}{l}\text { Access to knowledge } \\
\text { and information a }\end{array}$ & Program information and materials are appropriate. & 4.8 & 4.7 & 4.2 & 4.8 & 4.4 & 4.0 & 4.4 & 5.0 & 4.4 & 4.4 \\
\hline & & Program information and materials are engaging. & 4.8 & 4.4 & 4.3 & 4.5 & 4.3 & 3.0 & 4.4 & 4.0 & 4.3 & 4.1 \\
\hline & Available resources $^{a}$ & $\begin{array}{l}\text { I have the resources I need to promote the } \\
\text { program in my role. }\end{array}$ & 4.7 & 3.7 & 3.4 & 3.7 & 3.2 & 2.8 & 4.0 & 4.0 & 3.6 & 3.1 \\
\hline & $\begin{array}{l}\text { Leadership } \\
\text { engagement }^{\mathrm{a}}\end{array}$ & $\begin{array}{l}\text { The Coalition Steering Committee is supportive of } \\
\text { the program. }\end{array}$ & 3.9 & 4.3 & 4.1 & 4.5 & 4.6 & 5.0 & 4.8 & 4.5 & 4.3 & 4.1 \\
\hline & & $\begin{array}{l}\text { The Coalition Steering Committee encourages coali- } \\
\text { tion members to be involved in implementing the } \\
\text { program. }\end{array}$ & 3.6 & 4.2 & 4.1 & 4.5 & 4.4 & 5.0 & 4.5 & 4.8 & 4.3 & 4.1 \\
\hline & Tension for change ${ }^{a}$ & It is important that the program is implemented now. & 5.0 & 4.6 & 4.4 & 4.9 & 4.3 & 3.8 & 4.5 & 5.0 & 4.3 & 4.1 \\
\hline \multirow[t]{2}{*}{ Outer setting } & Cosmopolitanism $^{\text {a }}$ & $\begin{array}{l}\text { My employer encourages me to network with col- } \\
\text { leagues outside of my own setting. }\end{array}$ & 4.4 & 4.1 & 4.1 & 4.0 & 3.7 & 4.8 & 4.8 & 4.0 & 4.2 & 3.6 \\
\hline & $\begin{array}{l}\text { Farmer needs and } \\
\text { resources }^{\mathrm{a}}\end{array}$ & $\begin{array}{l}\text { Once implemented, the program will meet the needs } \\
\text { of my organization's target population. }\end{array}$ & 4.7 & 3.9 & 3.8 & 4.2 & 3.5 & 4.5 & 4.4 & 3.3 & 3.7 & 3.9 \\
\hline \multirow[t]{3}{*}{$\begin{array}{l}\text { Intervention } \\
\text { Characteristics }\end{array}$} & Cost $^{\mathrm{a}}$ & $\begin{array}{l}\text { The cost of the program has not prevented it from be- } \\
\text { ing implemented in my state. }\end{array}$ & 4.7 & 3.4 & 2.9 & 2.8 & 2.7 & 1.8 & 3.1 & 3.0 & 3.0 & 3.6 \\
\hline & $\begin{array}{l}\text { Design quality and } \\
\text { packaging a }^{\text {a }}\end{array}$ & $\begin{array}{l}\text { Program materials (including the website, promo- } \\
\text { tional materials, and information packets) are of high } \\
\text { quality. }\end{array}$ & 4.8 & 4.8 & 4.2 & 4.7 & 4.4 & 4.3 & 4.4 & 5.0 & 4.4 & 4.4 \\
\hline & $\begin{array}{l}\text { Evidence strength } \\
\text { and quality a }\end{array}$ & $\begin{array}{l}\text { Influential stakeholders (such as funders, manufac- } \\
\text { turers, or other influential individuals) are supportive } \\
\text { of the program. }\end{array}$ & 3.8 & 4.2 & 3.9 & 3.8 & 3.3 & 3.3 & 4.3 & 3.5 & 3.6 & 3.7 \\
\hline \multirow[t]{21}{*}{ Process } & $\begin{array}{l}\text { Reflecting and } \\
\text { evaluating }{ }^{\mathrm{a}}\end{array}$ & $\begin{array}{l}\text { Coalition updates are helpful in allowing me to re- } \\
\text { flect upon progress toward implementation of the } \\
\text { program. }\end{array}$ & 4.4 & 4.3 & 4.4 & 4.4 & 4.3 & 4.3 & 4.6 & 4.0 & 4.1 & 4.3 \\
\hline & $\begin{array}{l}\text { Engaging } \\
\text { (perceived role) b,c,d }\end{array}$ & Monitoring progress so that I can stay informed. & 0.8 & 0.9 & 1.0 & 0.8 & 0.9 & 0.8 & 1.0 & 1.0 & 0.9 & 0.6 \\
\hline & & $\begin{array}{l}\text { Providing feedback about activities that others are } \\
\text { planning and carrying out. }\end{array}$ & 0.8 & 0.5 & 0.8 & 0.6 & 0.6 & 0.3 & 0.7 & 0.8 & 0.5 & 0.4 \\
\hline & & $\begin{array}{l}\text { Sharing promotions and materials with partners out- } \\
\text { side of the coalition. }\end{array}$ & 1.0 & 0.8 & 0.9 & 0.8 & 0.6 & 0.5 & 1.0 & 0.8 & 0.8 & 0.6 \\
\hline & & $\begin{array}{l}\text { Helping plan implementation activities such as } \\
\text { events and fundraising. }\end{array}$ & 0.7 & 0.2 & 0.4 & 0.5 & 0.1 & 0.3 & 0.5 & 0.7 & 0.1 & 0.1 \\
\hline & & Participation in implementation events. & 0.7 & 0.4 & 0.4 & 0.3 & 0.2 & 0.3 & 0.7 & 0.0 & 0.2 & 0.3 \\
\hline & & Participation in fundraising. & 0.6 & 0.3 & 0.3 & 0.2 & 0.1 & 0.0 & 0.2 & 0.0 & 0.2 & 0.1 \\
\hline & $\begin{array}{l}\text { Engaging (actual ac- } \\
\text { tivity) c, d, e }\end{array}$ & Read coalition updates, information, or materials. & 2.8 & 1.6 & 2.0 & 1.5 & 1.5 & 1.5 & 2.3 & 1.0 & 1.6 & 1.7 \\
\hline & & Attended a coalition webinar or conference call. & 1.4 & 0.9 & 0.8 & 0.5 & 0.8 & 0.8 & 1.4 & 0.8 & 0.9 & 1.2 \\
\hline & & Attended a coalition in-person meeting. & 0.7 & 0.1 & 0.3 & 0.0 & 0.0 & 0.0 & 0.4 & 0.0 & 0.1 & 0.3 \\
\hline & & $\begin{array}{l}\text { Attended an event on behalf of the coalition or } \\
\text { program. }\end{array}$ & 0.8 & 0.0 & 0.4 & 0.0 & 0.2 & 0.0 & 0.6 & 0.3 & 0.3 & 0.4 \\
\hline & & $\begin{array}{l}\text { Provided feedback or suggestions on Coalition ac- } \\
\text { tivities or materials via email or a one-on-one phone } \\
\text { call. }\end{array}$ & 2.0 & 0.8 & 0.7 & 0.6 & 0.7 & 1.0 & 1.4 & 1.0 & 0.6 & 0.9 \\
\hline & & $\begin{array}{l}\text { Provided feedback or suggestions on coalition activi- } \\
\text { ties or materials during a coalition webinar, confer- } \\
\text { ence call, or in-person meeting. }\end{array}$ & 1.9 & 0.7 & 0.6 & 0.3 & 0.7 & 1.0 & 1.3 & 0.8 & 0.3 & 0.7 \\
\hline & & $\begin{array}{l}\text { Shared program information or promotions with a } \\
\text { group of individuals via social media, email distribu- } \\
\text { tion lists, or newsletters. }\end{array}$ & 1.5 & 0.7 & 1.2 & 0.5 & 0.7 & 0.8 & 1.5 & 0.3 & 0.9 & 1.1 \\
\hline & & $\begin{array}{l}\text { Incorporated program information into a presen- } \\
\text { tation or report that you were putting together for } \\
\text { another purpose. }\end{array}$ & 0.9 & 0.8 & 1.0 & 0.8 & 0.5 & 0.3 & 1.1 & 0.5 & 0.3 & 1.2 \\
\hline & & $\begin{array}{l}\text { Had a conversation about the program with an } \\
\text { individual(s) not involved in the Coalition. }\end{array}$ & 2.4 & 1.2 & 1.2 & 1.0 & 0.8 & 0.5 & 1.5 & 0.8 & 0.9 & 1.9 \\
\hline & & $\begin{array}{l}\text { Served as a spokesperson specifically for the } \\
\text { Coalition or program (through interviews, presenta- } \\
\text { tions, etc.). }\end{array}$ & 1.2 & 0.2 & 0.4 & 0.1 & 0.0 & 0.5 & 0.8 & 0.0 & 0.1 & 0.0 \\
\hline & & $\begin{array}{l}\text { Recruited new members to the coalition or connect- } \\
\text { ed coalition members with new partners. }\end{array}$ & 0.5 & 0.0 & 0.5 & 0.0 & 0.1 & 0.0 & 0.6 & 0.0 & 0.2 & 0.3 \\
\hline & & Helped arrange or plan coalition activities or events. & 1.3 & 0.0 & 0.2 & 0.0 & 0.0 & 0.0 & 0.4 & 0.0 & 0.0 & 0.1 \\
\hline & & $\begin{array}{l}\text { Helped submit a funding or resource request for the } \\
\text { program. }\end{array}$ & 0.7 & 0.2 & 0.2 & 0.0 & 0.1 & 0.0 & 0.1 & 0.0 & 0.1 & 0.1 \\
\hline & & $\begin{array}{l}\text { Met with potential funders to discuss funding the } \\
\text { program. }\end{array}$ & 0.7 & 0.3 & 0.1 & 0.3 & 0.0 & 0.0 & 0.1 & 0.5 & 0.2 & 0.4 \\
\hline
\end{tabular}


Table 4. continues

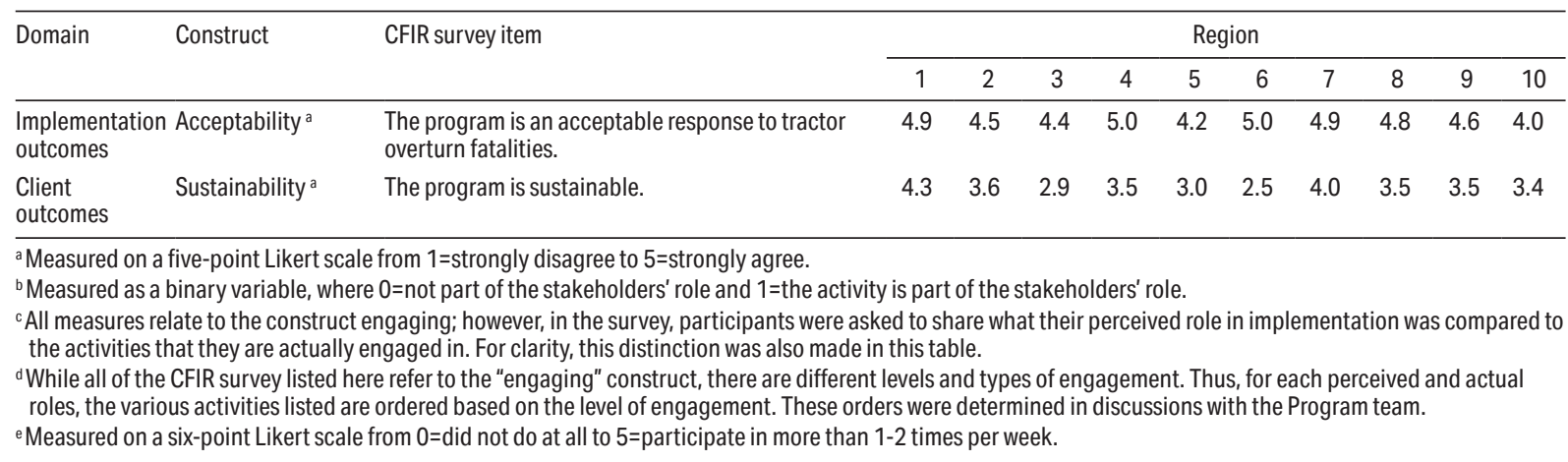

Table 5. Outcomes (average progress scores, number of intakes, and number of completed retrofits) by region number (as defined in table 2) and period, where period 1 =September 2016-February 2017, period 2 = March-August 2017, period 3 = September 2017-February 2018, and period 4=March-August 2018.

\begin{tabular}{|c|c|c|c|c|c|c|c|c|c|c|c|c|}
\hline \multirow[t]{2}{*}{ Region } & \multicolumn{4}{|c|}{ Progress } & \multicolumn{4}{|c|}{ Intakes $^{a}$} & \multicolumn{4}{|c|}{ Retrofits $^{a}$} \\
\hline & Period 1 & Period 2 & Period 3 & Period 4 & Period 1 & Period 2 & Period 3 & Period 4 & Period 1 & Period 2 & Period 3 & Period 4 \\
\hline 1 & 6.00 & 6.00 & 6.00 & 6.00 & 98 & 68 & 97 & 75 & 25 & 38 & 53 & 20 \\
\hline 2 & 4.25 & 4.25 & 4.75 & 4.75 & 6.5 & 10 & 8.75 & 8.75 & 0.5 & 0.75 & 1 & 0.75 \\
\hline 3 & 6.00 & 6.00 & 6.00 & 6.00 & 92 & 70.5 & 63 & 72 & 44.5 & 36 & 25 & 11.5 \\
\hline 4 & 0.11 & 0.22 & 0.67 & 0.78 & 0.3 & 2.9 & 3.0 & 1.6 & 0 & 0 & 0 & 0 \\
\hline 5 & 0.67 & 0.33 & 0.33 & 0.33 & 3.2 & 3.7 & 6.3 & 3.8 & 0 & 0 & 0.2 & 0 \\
\hline 6 & 0.00 & 0.00 & 0.00 & 0.25 & 1.75 & 1.5 & 2.25 & 2.5 & 0 & 0 & 0 & 0 \\
\hline 7 & 0.20 & 0.20 & 0.00 & 0.00 & 1.2 & 1.4 & 1.0 & 4.8 & 0 & 0 & 0 & 0 \\
\hline 8 & 1.00 & 0.00 & 0.00 & 0.00 & 0.25 & 2.0 & 1.75 & 2.0 & 0 & 0 & 0 & 0 \\
\hline 9 & 0.33 & 0.00 & 0.00 & 0.33 & 0.5 & 1.33 & 2.33 & 1.0 & 0 & 0 & 0 & 0 \\
\hline 10 & 0.43 & 0.43 & 0.43 & 0.29 & 0.14 & 0.28 & 1.0 & 1.71 & 0 & 0 & 0 & 0 \\
\hline
\end{tabular}

a Intakes and retrofits are shown as an average per period per state in the region.

than the time allotted in this study. Thus, if reassessed after another year, it is possible that progress scores would be higher.

Once state-allocated rebate funding has been secured, the social marketing campaign can be implemented in that state, thus triggering additional farmers to complete intakes and subsequently retrofit their tractors. Though there are intakes reported in each study region, the numbers are much lower in regions 4 through 10 . Still, these marginal successes indicate farmer interest in the NRRP, as without direct advertising in unfunded regions, farmers could only have discovered the program as a result of their own attempts to retrofit tractors.

In addition to CFIR survey items related to fundraising, the item "program materials are engaging" (item one) was highly correlated with all outcomes. This finding suggests that such materials (including both those that are targeted at stakeholders who can help secure state-allocated funding as well as farmers who may participate) may motivate stakeholders to take action by fundraising, signing up for the NRRP themselves, or further disseminating NRRP materials to others, and make those actions easier. This is supported by the basic premise of the construct (32), as well as principles of social marketing $(33,34)$, which suggest that materials that are easier to engage with are more likely to promote the anticipated behavior. This principle was demonstrated in developing the social marketing messages to increase farmer participation in the ROPS rebate programs $(22,25)$.

Finally, the CFIR survey item "stakeholders understand their role to include providing feedback about implementation activities and fundraising," (item four) was also highly correlated with all three outcome measures. In these cases, individuals who are providing feedback about program implementation and fundraising may feel a greater sense of ownership, thus motivating them to be further involved. Ownership has often been cited as a key motivator for employees, stakeholders, and other populations (35-38), as it facilitates the transformation of individuals' roles and responsibilities within an organization or organized effort (38). In the public health sector, community coalitions have focused on ownership as an indicator of increased engagement and improved health outcomes (39).

Two CFIR survey items were highly correlated with 
Table 6. Correlation between consolidated framework for implementation research (CFIR) survey items and outcomes: coefficients and P-values for all correlations where rho $\geq 0.50$. Significant P-values $(\leq 0.05)$ are bolded.

\begin{tabular}{|c|c|c|c|c|c|c|c|c|c|}
\hline \multirow[t]{2}{*}{ Domain } & \multirow[t]{2}{*}{ Construct } & \multicolumn{2}{|c|}{ CFIR survey item } & \multicolumn{2}{|c|}{ Progress } & \multicolumn{2}{|c|}{ Intakes } & \multicolumn{2}{|c|}{ Retrofits } \\
\hline & & $\#$ & Item Description & rho & P-value & rho & P-value & rho & P-value \\
\hline \multirow[t]{3}{*}{ Inner setting } & $\begin{array}{l}\text { Access to knowledge and } \\
\text { Information }\end{array}$ & 1 & The program materials are engaging & 0.687 & 0.028 & 0.648 & 0.043 & 0.567 & 0.088 \\
\hline & Leadership engagement & 2 & $\begin{array}{l}\text { The Coalition Steering Committee encourages members to } \\
\text { be involved in implementing the program }\end{array}$ & -0.729 & 0.017 & & & -0.731 & 0.016 \\
\hline & & 3 & $\begin{array}{l}\text { The Coalition Seering Committee is supportive of the } \\
\text { program }\end{array}$ & -0.705 & 0.023 & & & -0.574 & 0.083 \\
\hline \multirow[t]{5}{*}{ Process } & Engaging (perceived role) a & 4 & $\begin{array}{l}\text { Providing feedback about activities that others are planning } \\
\text { and carrying out }\end{array}$ & 0.571 & 0.084 & 0.564 & 0.090 & 0.594 & 0.070 \\
\hline & & 5 & Participation in implementation events & & & 0.500 & 0.141 & & \\
\hline & & 6 & Participation in fundraising & 0.691 & 0.027 & 0.543 & 0.105 & 0.687 & 0.028 \\
\hline & Engaging (actual role) ${ }^{a}$ & 7 & Submitted a funding or resource request for the program & 0.586 & 0.075 & 0.505 & 0.137 & 0.756 & 0.012 \\
\hline & Reflecting and evaluating & 8 & $\begin{array}{l}\text { Coalition updates are helpful in allowing me to reflect upon } \\
\text { progress toward implementation of the program }\end{array}$ & & & 0.583 & 0.077 & & \\
\hline
\end{tabular}

all measures relate to the construct "engaging"; however, in the survey, participants were asked to share what their perceived role in implementation was compared to the activities that they are actually engaged in. For clarity, this distinction was also made in this table.

at least two outcome measures, again, indicating practical significance. Two measures of leadership engagement, "the NTSC steering committee encourages members to be involved in implementing the program," and "the NTSC steering committee is supportive of the program," (items two and three) were both highly negatively correlated with progress and retrofits. This is perhaps the most surprising finding, in that one would expect the opposite to occur - a more highly engaged leadership should be correlated with improved outcomes. In a qualitative portion of this study (Tinc et al, forthcoming); the study team explored this finding in interviews with steering committee, general NTSC, and non-NTSC stakeholders who identified two possible explanations. First, it was suggested that because the steering committee is comprised of well-known and well-respected individuals in the agricultural research community, the program may be seen as a "top-down" approach. Thus, others may be less motivated to engage in the implementation process by raising funds or promoting the program in their state. This is consistent with the stakeholder engagement literature, which recommends collaborative partnerships, reciprocal relationships, and co-learning, among other strategies for increasing engagement $(40,41)$. However; some psychology research contradicts this observation by suggesting that individuals are more likely to engage in behaviors (such as being involved in the NRRP implementation) that are promoted by authority figures, which could include members of the steering committee (42). Second, it was suggested that the states with active and sufficiently funded programs may have gotten to that point without the help of steering committee members. Thus, those who have state-allocated funding in place may not place value on steering committee members' contributions.

The CFIR survey items "NTSC updates are helpful in allowing me to reflect upon progress toward imple- mentation of the program" and "participation in implementation events (perceived role)," (items eight and five) were both highly correlated with intakes, but not with the other two outcome variables. This might suggest that both of these activities are enough to encourage stakeholders to spread the word about the program to the target population, but do not motivate stakeholders to dedicate time to fundraising activities.

The results of this study are immediately important, in that they provide guidance for continuing the implementation of the NRRP. Based on these results, it is important to consider barriers to stakeholder engagement and how to remove those barriers, especially for NTSC members and stakeholders in regions with low numbers of intakes and retrofits. In addition, the alarmingly high negative correlations between CFIR survey items related to steering committee engagement and outcome variables suggest that more needs to be done to encourage full-NTSC communication and excitement about the NRRP. A social networking analysis focused on NTSC member interactions is currently underway and will provide valuable information related to NTSC member communications and collaboration.

In addition to the primary findings of this study, it is also relevant to comment on the utility of the CFIR in occupational safety settings, such as this one. A prior study by the research team demonstrated that while the CFIR was applicable in agricultural safety settings, there were some challenges applying the CFIR to scale-up initiatives versus single site implementation studies (12). This sentiment was echoed in a review of CFIR use published in 2016 (11). The results of this study indicated that initial assessments of the utility of the CFIR within agricultural safety settings were accurate. However, further assessment of the CFIR's utility using other occupational safety interventions would be important in confirming this finding. 
Limitations

There are four main limitations to this study. First, only constructs described by the CFIR were evaluated for correlation with ROPS outcomes and only a portion of the total possible CFIR constructs were included in this portion of the study. Thus, there may be additional factors relevant to the implementation of the NRRP that were not explored in this study. However, additional constructs would have made the survey longer and impacted response rates so the decision was based on achieving a balance between these potential research design challenges. Additionally, qualitative interviews with NTSC members and non-members have been used to elicit additional information about the program implementation and clarify survey responses (Tinc et al, forthcoming).

Second, the sample size for this study is quite small, which is primarily due to the size of the NTSC and location of its members. NTSC members do not exist in all states, and thus survey responses were also not available for all states and so regions were used as the units of analysis. It is possible that if study results were to be compared between individuals or states, the analyses presented here might result in different outcomes. Thus, these conclusions should be considered in light of this fact.

Third, the average response rate for the CFIR surveys was only $57 \%$. While this is a relatively promising response rate on such surveys, it is possible that the results presented here could differ from the results had all NTSC members responded to the various survey requests. In particular, the individuals who did not respond to the survey requests may have drastically different viewpoints of the implementation process. It is also possible that, had all NTSC members responded to all survey requests, the correlations presented here may have been different.

Finally, it should be acknowledged that the study, being observational in nature, cannot establish cause and effect. Whether or not a change in a CFIR item will produce a change in outcomes such as intakes and retrofits, cannot be established with certainty.

\section{Concluding remarks}

This study provided insight into key factors that have influenced the NRRP implementation, including both those that have hindered and helped the effort. In continuing with the NRRP implementation, it may be helpful to consult the stakeholder and employee engagement literature for guidance and strategies. For example, modifying communication strategies, engaging in shared leadership strategies, and simultaneously targeting emotion, beliefs, and behaviors could help improve stake- holder engagement $(37,38)$. Further work to evaluate changes in the CFIR survey items discussed in this manuscript would be beneficial to assess the impact of such strategies.

Outside of the NRRP implementation, these results could be useful for others hoping to attempt similarly structured implementation initiatives. First, the evaluation structure utilized in this study could be applied in other areas of occupational and public health. Second, the key findings may be useful to consider when planning implementation studies that will require involving a wide variety of stakeholders.

\section{Acknowledgements}

The authors would like to thank Nicole Krupa (Bassett Research Institute Center for Biostatistics) for assistance with data management and Deb Dalton, Rebecca Russell, Nora Lindner, and Alissa Kent (Northeast Center) for their assistance collecting surveys and outcome data.

\section{References}

1. Bureau of Labor Statistics. Census of Fatal Occupational Injuries Charts, 1992-2017 (final data) Washington, D.C.: United States Department of Labor; 2019 [accessed August 21, 2018]. Available from: https://www.bls.gov/iif/oshcfoil. htm.

2. Bureau of Labor Statistics. Industry Injury and Illness Data 2017 Washington, D.C.: United States Department of Labor; 2016 [accessed February 13, 2019]. Available from: https:// www.bls.gov/iif/oshsum.htm.

3. Leigh JP, Du J, McCurdy SA. An estimate of the U.S. government's undercount of nonfatal occupational injuries and illnesses in agriculture. Ann Epidemiol 2014 Apr;24(4):254-9. https://doi.org/10.1016/j. annepidem.2014.01.006.

4. Howard J. Informing public health policy and practice: the strategic management of research processes and organizations. Governance (Oxford) 2009;22(2):203-16. https://doi.org/10.1111/j.1468-0491.2009.01432.x.

5. Tinc PJ, Gadomski A, Sorensen JA, Weinehall L, Jenkins $\mathrm{P}$, Lindvall K. Adapting the T0-T4 implementation science model to occupational health and safety in agriculture, forestry, and fishing: A scoping review. Am J Ind Med 2018 Jan;61(1):51-62. https://doi.org/10.1002/ajim.22787.

6. Schulte PA, Cunningham TR, Nickels L, Felknor S, Guerin $\mathrm{R}$, Blosser $\mathrm{F}$ et al. Translation research in occupational safety and health: A proposed framework. Am J Ind Med 2017 Dec;60(12):1011-22. https://doi.org/10.1002/ ajim.22780. 
7. CFIR Research Team. Consolidated Framework for Implementation Science Ann Arbor, MI: Center for Clinical Management Research; 2017 [May 3, 2017]. Available from: http://www.cfirguide.org/.

8. Damschroder LJ, Aron DC, Keith RE, Kirsh SR, Alexander JA, Lowery JC. Fostering implementation of health services research findings into practice: a consolidated framework for advancing implementation science. Implement Sci 2009 Aug;4(1):50. https://doi.org/10.1186/1748-5908-4-50.

9. Proctor E, Silmere H, Raghavan R, Hovmand P, Aarons $\mathrm{G}$, Bunger A et al. Outcomes for implementation research: conceptual distinctions, measurement challenges, and research agenda. Adm Policy Ment Health 2011 Mar;38(2):65-76. https://doi.org/10.1007/s10488-0100319-7.

10. Fernandez ME, Walker TJ, Weiner BJ, Calo WA, Liang S, Risendal B et al. Developing measures to assess constructs from the Inner Setting domain of the Consolidated Framework for Implementation Research. Implement Sci 2018 Mar;13(1):52. https://doi.org/10.1186/s13012-0180736-7.

11. Kirk MA, Kelley C, Yankey N, Birken SA, Abadie B, Damschroder L. A systematic review of the use of the Consolidated Framework for Implementation Research. Implement Sci 2016 May;11:72. https://doi.org/10.1186/ s13012-016-0437-z.

12. Tinc PJ, Gadomski A, Sorensen JA, Weinehall L, Jenkins $\mathrm{P}$, Lindvall K. Applying the Consolidated Framework for implementation research to agricultural safety and health: Barriers, facilitators, and evaluation opportunities. Saf Sci 2018;107:99-108. https://doi.org/10.1016/j. ssci.2018.04.008.

13. Murphy DJ, Myers J, McKenzie EA Jr, Cavaletto R, May J, Sorensen J. Tractors and rollover protection in the United States. J Agromed 2010 Jul;15(3):249-63. https://doi.org/10 $.1080 / 1059924 X .2010 .484309$.

14. American Society of Agricultural and Biological Engineers (ASABE). ASABE Technical Library: Standards. 2014.

15. Loringer KA, Myers JR. Tracking the prevalence of rollover protective structures on U.S. farm tractors: 1993, 2001, and 2004. J Safety Res 2008;39(5):509-17. https://doi. org/10.1016/j.jsr.2008.08.003.

16. Sorensen JA, May JJ, Jenkins PL, Jones AM, EarleRichardson GB. Risk perceptions, barriers, and motivators to tractor ROPS retrofitting in the New York state farm community. J Agric Saf Health 2006 Aug;12(3):215-26. Epub 2006 Sep 20. https://doi.org/10.13031/2013.21229.

17. Sorensen JA, May JJ, Paap K, Purschwitz MA, Emmelin $M$. Encouraging farmers to retrofit tractors: a qualitative analysis of risk perceptions among a group of highrisk farmers in New York. J Agric Saf Health 2008 Jan;14(1):105-17. https://doi.org/10.13031/2013.24127.

18. Sorensen JA, May J, Ostby-Malling R, Lehmen T, Strand J, Stenlund $\mathrm{H}$ et al. Encouraging the installation of rollover protective structures in New York State: the design of a social marketing intervention. Scand
J Public Health 2008 Nov;36(8):859-69. https://doi. org/10.1177/1403494808089655.

19. Jenkins PL, Sorensen JA, Yoder A, Myers M, Murphy D, Cook $\mathrm{G}$ et al. Prominent barriers and motivators to installing ROPS: an analysis of survey responses from Pennsylvania and Vermont. J Agric Saf Health 2012 Apr;18(2):103-12. https://doi.org/10.13031/2013.41328.

20. Sorensen J, Emmelin M, Stenlund H, May J, Lundqvist P. Social marketing for injury prevention: changing risk perceptions and safety-related behaviors among New York farmers. Umeå: Umeå universitet; 2009.

21. Sorensen JA, Jenkins PL, Bayes B, Madden E, Purschwitz MA, May JJ. Increases in ROPS pricing from 2006-2012 and the impact on ROPS demand. J Agric Saf Health 2013 Apr;19(2):115-24.

22. Sorensen JA, Jenkins PL, Emmelin M, Stenlund H, Weinehall L, Earle-Richardson GB et al. The social marketing of safety behaviors: a quasi-randomized controlled trial of tractor retrofitting incentives. Am J Public Health 2011 Apr;101(4):678-84. https://doi.org/10.2105/ AJPH.2010.200162.

23. Sorensen JA, McKenzie T Jr, Purschwitz M, Fiske T, Jenkins PL, O'Hara P et al. Results from inspections of farmer-installed rollover protective structures. J Agromed 2011 Jan;16(1):19-29. https://doi.org/10.1080/105992 4X.2011.532762.

24. Sorensen JA, Jenkins P, Bayes B, Clark S, May JJ. Costeffectiveness of a ROPS social marketing campaign. J Agric Saf Health 2010 Jan;16(1):31-40. https://doi. org/10.13031/2013.29247.

25. Sorensen JA, May J, O'Hara R, Ostby R, Lehman T, Viebrock S et al. Evaluating Tractor Safety Messages: A Concept Development Project. Soc Mar Q 2008;14(4):2244. https://doi.org/10.1080/15245000802549926.

26. Northeast Center for Occupational Health and Safety. National ROPS Rebate program 2017 [accessed May 3, 2017]. Available from: https://www.nycamhoutreach.com/ropsr4u/.

27. Sorensen J, Tinc P. NIOSH Science Blog [Internet]. Atlanta, GA: Center for Disease Control. 2014. [cited 2015]. Available from: https://blogs.cdc.gov/niosh-science-blog/2014/08/12/ rops $2 /$.

28. Tinc PJ, Ayers PD, May JJ, Purschwitz MA, Sorensen JA. Creating a national coalition to address tractor overturn fatalities. J Agric Saf Health 2015 Apr;21(2):105-12.

29. Tinc PJ, Ayers P, May JJ, Purschwitz MA, Park S, Bayes $\mathrm{B}$, et al. Implementing a National Tractor Safety program: Using "Whole System in a Room" to Mobilize Partners and Implement Solutions. J Agromedicine. 2016;21(2):127-31. https://doi.org/10.1080/1059924X.2016.1142916.

30. Tinc PJ, Sorensen JA. NIOSH Science Blog [Internet]. Atlanta, GA: Centers for Disease Control and Prevention. 2017. [cited 2017]. Available from: https://blogs.cdc.gov/ niosh-science-blog/2017/06/30/rops-2/.

31. Dillman DA, Smyth JD, Christian LM. Internet, Phone, Mail, and Mixed-Mode Surveys: The Tailored Design Method, 4th 
Edition: Wiley; 2014.

32. CFIR Research Team. Design Quality and Packaging Ann Arbor, MI: CFIR Research Team-Center for Clinical Management Research; 2018 [accessed November 8, 2018]. Available from: https://cfirguide.org/constructs/designquality-packaging/.

33. Graham ID, Logan J. Innovations in knowledge transfer and continuity of care. Can J Nurs Res 2004 Jun;36(2):89-103.

34. Grier S, Bryant CA. Social marketing in public health. Annu Rev Public Health 2005;26:319-39. https://doi.org/10.1146/ annurev.publhealth.26.021304.144610

35. Hung D, Wong E, Anderson K, Hereford J. PS2-14: Ready to Change? The Role of Employee Engagement, Ownership, and Participation in Managing Change. Clin Med Res 2013;11(3):159. https://doi.org/10.3121/cmr.2013.1176. ps2-14.

36. Schulz AJ, Israel BA, Lantz P. Instrument for evaluating dimensions of group dynamics within community-based participatory research partnerships. Eval program Plann 2003;26(3):249-62. https://doi.org/10.1016/S01497189(03)00029-6.

37. Forsythe LP, Ellis LE, Edmundson L, Sabharwal R, Rein A, Konopka $\mathrm{K}$ et al. Patient and Stakeholder Engagement in the PCORI Pilot Projects: Description and Lessons Learned. J Gen Intern Med 2016 Jan;31(1):13-21. https:// doi.org/10.1007/s11606-015-3450-z.
38. Graffigna G. Is a Transdisciplinary Theory of Engagement in Organized Settings Possible? A Concept Analysis of the Literature on Employee Engagement, Consumer Engagement and Patient Engagement. Front Psychol 2017 Jul;8:872. https://doi.org/10.3389/fpsyg.2017.00872.

39. Armbruster C, Gale B, Brady J, Thompson N. Perceived ownership in a community coalition. Public Health Nurs 1999 Feb;16(1):17-22. Epub 1999 Mar 13. https://doi. org/10.1046/j.1525-1446.1999.00017.x.

40. Goodman MS, Sanders Thompson VL. The science of stakeholder engagement in research: classification, implementation, and evaluation. Transl Behav Med 2017 Sep;7(3):486-91. https://doi.org/10.1007/s13142-0170495-z.

41. Ray KN, Miller E. Strengthening stakeholder-engaged research and research on stakeholder engagement. J Comp Eff Res 2017 Jun;6(4):375-89. https://doi.org/10.2217/cer2016-0096.

42. Cialdini R. Influence: The Psychology of Persuassion. New York, NY: Collins Bussiness Essentials; 2007.

Received for publication: 115 January 2019 